\title{
RESPON MAHASISWA KUALIFIKASI AKADEMIK GURU MADRASAH DINIYAH TERHADAP PEMBELAJARAN AL-ISLAM DAN KEMUHAMMADIYAHAN
}

\author{
Ibnu Habibi' ${ }^{1)}$, Abdul Bashith ${ }^{2)}$ Ilfi Nurdiana ${ }^{3)}$ \\ ${ }^{1}$ STIT Muhammadiyah Bojonegoro \\ email: nizamhabibi259@gmail.com \\ ${ }^{2}$ UIN Maulana Malik Ibrahim Malang \\ email: abbash98@pips.uin-malang.ac.id \\ ${ }^{3}$ UIN Maulana Malik Ibrahim Malang \\ email: ilfi_nur@yahoo.com
}

\begin{abstract}
Abstrack : This study aims to determine the response of students of the Madin qualification program to Al-Islam and Muhammadiyah (AIK) courses as well as the implementation of the AIK course learning at STIT Muhammadiyah Bojonegoro where almost all of these students have Nahdlatul Ulama (NU) background. This study used a qualitative descriptive analytic method, with a focus on research of 5th semester students with a total number of respondents as many as 29 students who were the 2018 class. Data collection techniques used in this study included observation, interviews, questionnaires and documentation. The results of this study can be given the meaning that (1) the provision of AIK courses to Madin students is well accepted and necessary to increase knowledge insight; (2) based on the results of interviews with students in the class, the lecturer gave a very good understanding and did not blame other understandings; (3) the material is in accordance with the curriculum and can provide great influence on the Muhammadiyah perspective so that it allows them to understand Muhammadiyah.
\end{abstract}

Keywords: Student response, Madin Teacher, AIK

Abstrak : Penelitian ini bertujuan untuk mengetahui respon mahasiswa program kualifikasi Madin terhadap mata kuliah Agama Islam dan KeMuhammadiyahan (AIK) serta pelaksanaan pembelajaran mata kuliah AIK di STIT Muhammadiyah Bojonegoro dimana hampir semua mahasiswa tersebut memiliki latar belakang Nahdlatul Ulama (NU). Penelitian ini menggunakan metode deskriptif analitik kualitatif, dengan fokus penelitian pada mahasiswa semester 5 dengan jumlah responden sebanyak 29 mahasiswa yang merupakan angkatan 2018. Teknik pengumpulan data yang digunakan dalam penelitian ini meliputi observasi, wawancara, angket dan dokumentasi. Hasil penelitian ini dapat disimpulkan bahwa (1) pemberian mata kuliah AIK kepada mahasiswa Madin diterima dengan baik dan diperlukan untuk menambah wawasan pengetahuan; (2) berdasarkan hasil wawancara dengan mahasiswa di kelas, dosen memberikan pemahaman yang sangat baik dan tidak menyalahkan pemahaman lain; (3) Materi yang sesuai dengan kurikulum dan dapat memberikan pengaruh yang besar terhadap cara pandang Muhammadiyah sehingga memungkinkan mereka memahami Muhammadiyah

Kata kunci:Respon mahasiswa, Guru Madin, AIK

\section{PENDAHULUAN}

Lembaga pendidikan tertinggi yang memiliki peranan penting terhadap pembagunan bangsa adalah Perguruan Tinggi. Darinya telah dan akan lahir kaum intelektul dan terdidik dengan harapan mampu membawa ke arah yang lebih baik bagi kehidupan bangsa. Sebuah bangsa dikatakan maju apabila bangsa itu memiliki sumberdaya manusia yang berkualitas sehingga melahirkan kemajuan ilmu pengetahuan dan teknologi. Sebagai upayanya dirancang dan diberikan Kurikulum Pendidikan Agama Islam (PAI) di Perguruan Tinggi.

Dalam Sistem Pendidikan Nasional Pendidikan Agama Islam (PAI) merupakan bagian yang tidak terpisahkan sebagai program kurikuler. Oleh karena itu, seluruh peserta didik (siswa dan mahasiswa) muslim disemua jalur dan jenjang pendidikan akan mendapatkan kurikulum dan pembelajaran PAI yang seakligus sebagai penjamin dan berperan dalam mencapai tujuan pendidikan nasional. 
Pendidikan agama dirancang
dengan maksud untuk membentuk
mahasiswa agar melahirkan kebaikan untuk
masyarakatnya dan juga pada dirinya
sendiri, dalam aspek ibadah dan
mu'amalah, terhadap urusan kepentingan
orang banyak terlebih urusan pribadi.
Harapan lain dari pendidikan agama adalah
mampu menelurkan pribadi yang saleh,
mempunyai budi luhur bagi calon anggota
masyarakat, dan memiliki kepribadian yang
penuh tauladan bagi calon-calon pemimpin. Tujuan Pendidikan agama Islam di Perguruan Tinggi adalah untuk memberikan landasan pengembangan kepribadian kepada mahasiswa agar menjadi kaum intelektual yang beriman dan bertaqwa kepada Tuhan Yang Maha Esa, berbudi pekerti luhur, berfikir filosofis, bersikap rasional dan dinamis, berpandangan luas, ikut serta dalam kerjasama antar umat beragama dalam rangka pengembangan dan pemanfaatan ilmu dan teknologi serta seni untuk kepentingan nasional (Wahyuddin, et.all, 2009:4).

Muhammadiyah sebagai sebuah persyarikatan yang memiliki Perguruan Tinggi juga menjadikan Pendidikan Agama Islam sebagai pionir dalam mencapai tujuan pendidikan Nasional. PAI yang dipadukan dengan mata kuliah Kemuhammadiyahan sebagai mata kuliah penciri di perguruang tinggi Muhammadiyah atau lebih dikenal dengan mata kuliah Al-Islam dan Kemuhammadiyahan (AIK) diberikan kepada mahasiswa yang sifatnya wajib dan menjadi satu kesatuan dalam kurikulum , dengan harapan dapat memberikan pengaruh terhadap mahasiswa terutama karakter, baik ketika proses pembelajaran berlangsung terlebih setelah menjadi Alumni (Fariadi, 2010:62), sehingga target yang akan dicapai yaitu menjadikan lulusan pendidikan muhammadiyah yang memiliki akidah yang benar, akhlak yang mulia, cerdas, terampil dan siap mengabdi bagi kepentingan agama Islam dan masyarakat akan terwujud.

Menurut Majelis Pendidikan Tinggi Muhammadiyah (Tim Pedoman Pendidikan Al-Islam dan Kemuhammadiyahan, 2013:13) pendidikan AIK jika dibahas dari aspek teologis dan filosofis memiliki 5 (lima) poin diskursus yaitu Pemikiran Keagamaan, Diskursus tentang Tuhan, Diskursus tentang Nabi, Diskursus Manusia Utama, dan Diskursus tentang pandangan hidup. Visi pendidikan Muhammadiyah adalah "Terbentuknya manusia pembelajar yang taqwa, berakal mulia, berkemajuan dan unggul dalam IPTEKS sebagai perwujudan tajdid dakwah amar ma'ruf nahi munkar" (Toto Suharto, 2014:99). Pendidikan Muhammadiyah merupakan pendidikan Islam modern yang memadukan agama dengan kehidupan dan antara iman dan kemajuan yang holistik. Sebagaimana dengan pernyataan KH. Ahmad Dahlan bahwa pendidikan yang harus di tegakkan dan dilaksanakan untuk modal pembangunan bangsa yaitu pendidikan akhlak, pendidikan individu dan pendidikan sosial. Harapannya dari rahim pendidikan Muhammadiyah dapat melahirkan generasi muslim terpelajar yang kuat iman dan kepribadiannya, sekaligus mampu menjawab dan menghadapi tantangan zaman (Syamsul Hidayat, 2012: 175).

AIK telah diberikan di Perguruan Tinggi Muhammadiyah, akan tetapi belum maksimal dalam penerapan nilai-nilai $\mathrm{Al}$ Islam dan Kemuhammadiyahan kepada mahasiswa dikarenakan; kekurangan SDM khususnya yang memiliki bidang keahlian Pendidikan Agama dan AIK, adanya asumsi mahasiswa bahwa nilai-nilai $\mathrm{Al}$ Islam dan Kemuhammadiyahan bukan menjadi tanggung jawabnya melainkan tanggung jawab dari Dosen yang mengampu mata kuliah tersebut. Persepsi mahasiswa terhadap nilai-nilai Al-Islam dan Kemuhammadiyahan hanyalah 
merupakan materi-materi pembelajaran yang mahasiswa peroleh dari mata kuliah Al-Islam dan Kemuhammadiyahan selama perkuliahan (Tri Saswandi, dkk., 2019:27).

Persepsip dan asumsi tersebut menjadi wajar karena mahasiswa yang memempuh studi di perguruan tinggi Muhammadiyah heterogen atau berasal dari latar belakang yang berbeda. Latar belakang pendidikan mahasiswa yang heterogen menjadikan beragam pula tingkat respon mereka terhadap mata kuliah AIK. Sekolah Tinggi Ilmu Tarbiyah (STIT) Muhammadiyah Bojonegoro memilki input Mahasiswa yang erbeda khususnya Mahasiswa dari Beasiswa Program Kualifikasi Guru Madrasah Diniyah dari Pememerintah Provinsi Jawa Timur.

Sebagaimana diketahui bahwa dengan disahkan dan diberlakukannya Peraturan Pemerintah Nomor 55 Tahun 2007 tentang Pendidikan Agama dan Pendidikan Keagamaan, menunjukkan bahwa keberadaan Madrasah Diniyah ke depan akan semakin eksis. Oleh karena itu pemerintah provinsi melalui Lembaga Pengembangan Pendidikan Diniyah (LPPD) Jawa Timur dengan merangkul para kyai pondok pesantren dan beberapa Perguruan Tinggi Agama Islam (PTAIS) terus berupaya melakukan standarisasi Madrasah Diniyah agar statusnya sama/setara dengan lembaga pendidikan formal lainnya di jawa timur. Implementasi Kebijakan Pemerintah Provinsi Jawa Timur tentang program peningkatan kualifikasi akademik guru guru Madrasah Diniyah mulai tahun 2006 sampai dengan 2010 telah mencapai 4.370 orang guru yang dikuliahkan program strata satu (S1) di 34 perguruan tinggi yang tersebar di 30 Kabupaten/Kota (M. Nafiur Rofiq, 2011:54). Dan Sekolah Tinggi Ilmu Tarbiyah (STIT) Muhammadiyah Bojonegoro menjadi salah satu Perguruan
Tinggi yang mendapatkan Program tersebut.

Oleh karena itu menarik untuk diteliti bagaimana respon Mahasiswa Madin terhadap Mata Kuliah AIK di STIT Muhammadiyah Bojonegoro yang hampir semua Mahasiswanya dan Madrasah Diniyah berafiliasi pada Nahdlatul Ulama' (NU).

\section{METODE PENELITIAN}

Pendekatan yang digunakan dalam penelitian ini adalah pendekatan kualitatif deskriptif. Penelitian kualitatif lebih menekankan pada proses yang diambil dari fenomena-fenomena di balik realita yang ada, kemudian ditarik kesimpulannya dengan serangkaian kata atau kalimat. Seperti yang dinyatakan oleh Lexy J. Moleong bahwa penelitian kualitatif adalah penelitian yang bermaksud untuk memahami fenomena tentang apa yang dialami oleh subjek penelitian misalnya perilaku, persepsi, motivasi, tindakan dll, secara holistik, dan dengan cara deskripsi dalam bentuk kata-kata dan bahasa pada suatu konteks khusus yang alamiah dan dengan memenfaatkan berbagai cara alamiah ( Lexy J Moleong, 2007:6).

Penelitian ini dilaksanakan di Sekolah Tinggi Ilmu Tarbiyah (STIT) Muhammadiyah Bojonegoro dengan sumber data dalam penelitian ini adalah kurikulum AIK, dosen AIK dan mahasiswa. Teknik pengumpulan data yang digunakan dalam penelitian ini meliputi: Observasi yaitu mengamati pola pembinaan, proses pembelajaran dan segala macam aktivitas lainnya; Wawancara dengan responden dosen AIK, Pimpinan dan Mahasiswa Madin; angket untuk mengetahui respon Mahasiwa dan dan Dokumentasi. Penelitian ini menggunakan teknik analisis data berupa analisis data kualitatif yang memberi penjelasan dan keterangan dari 
hasil penelitian yang diperoleh dan dapat digunakan untuk kesimpulan dan saran. Sedangkan Proses dan teknik analisis yang digunakan adalah analisis model Milles dan Huberman yaitu dapat melalui tiga proses yaitu proses reduksi data, penyajian data, dan menarik kesimpulan atau verifikasi (Miles, Mattew B dan A. Michael Huberman, 2007: 16-21).

\section{HASIL DAN PEMBAHASAN Kualifikasi Akademik Guru Madrasah Dieniyah}

Dalam kurun waktu tahun 2006 hingga tahun 2015 sebagaimana tertuang dalam RPJMD Provinsi Jawa Timur tahun 2014-2019 (Lampiran Perda Provinsi Jawa Timur Nomor 3, 2014: 2), Pemerintah Provinsi Jawa Timur memiliki kebijakan di bidang peningkatan Sumber Daya Manusia (SDM) pada sektor pendidikan kegamaan Islam khususnya pendidikan Diniyah, berupa: "(1) pemberdayaan pendidikan diniyah dan Pondok Pesantren salafiyah melalui bantuan operasional sekolah secara memadai, dan/atau subsidi/hibah dalam bentuk block grant atau imbal swadaya untuk meningkatkan mutu pelayanan pendidikan keagamaan yang setara pendidikan umum dan (2) peningkatan kuantitas dan kualitas tenaga pendidik (guru/ustadz) pada lembaga pendidikan Diniyah dan Pondok Pesantren salafiyah secara lebih merata, bermutu, tepat lokasi, terutama untuk daerah pedesaan, wilayah terpencil, dan kepulauan" (Bappeda Jatim, 2014).

Melalui pengembangan Madrasah Diniyah, Pemerintah Provinsi Jawa Timur telah mengembangkan program pendidikan agama dan keagamaan. Pada program tersebut telah dialokasikan dana Bantuan Sosial Daerah kepada para guru, siswa atau santri Madrasah Diniyah dalam jumlah yang cukup memadai. Dana tersebut antara lain diberikan dalam bentuk beasiswa penyetaraan standar guru Madrasah Diniyah. Bantuan beasiswa diberikan kepada Mereka yang selama ini berstatus lulusan SMA atau D II untuk memperoleh pendidikan S1 (Dinas Pendidikan Provinsi Jawa Timur, 2015:20).

Hingga saat ini di Jawa Timur kurang lebih terdapat 20.011 lembaga Madrasah Diniyah dengan banyak santri sejumlah 1.755.524 santri. Jika dibandingkan, jumlah santri adalah $23 \%$ nya dari siswa pendidikan formal (SD-SMA/MI-MA dan yang sederajat) dengan jumlah total sebanyak 7.583.508 siswa, dan itu bukanlah jumlah yang sedikit secara kuantitas. Dari jumlah yang ada dapat diartikan bahwa yang terlibat dalam penyelenggaraan Madrasah Diniyah sangat banyak, baik orang tua, ustadz, maupun masyarakat dan pengelola. Dan tentunya dampak yang ditimbulkan terhadap pemerintah, pembangunan, dan masyarakat sangat besar sekali. Untuk mengembangkan Madrasah Diniyah, salah satu kebijakan Pemerintah Provinsi Jawa Timur adalah program peningkatan kualitas guru Madrasah Diniyah. Dijelaskan dalam pedoman penyelenggaraan bahwa "Program peningkatan kualitas guru Madrasah Diniyah merupakan bantuan beasiswa kepada guru Madrasah Diniyah untuk mencapai jenjang pendidikan S1 pada Program Studi Pendidikan Agama Islam (PAI) atau Pendidikan Bahasa Arab (PBA) dan ditempuh selama delapan semester" (M. Nafiur Rofiq, 2011:54).

Tujuan program Peningkatan Kualitas Guru Madrasah Diniyah: 1) Meningkatkan standar mutu akademik pendidikan/Madrasah Diniyah; 2) Meningkatkan standar kualifikasi akademik guru Madrasah Diniyah; 3) Meningkatkan kompetensi guru Madrasah Diniyah; 4) Mengupayakan sertifikasi guru Madrasah Diniyah; dan 5) Mengembangkan pendidikan/Madrasah Diniyah sebagai 
satuan pendidikan dan setara dengan satuan pendidikan lain sesuai peraturan perundang-undangan" (Pemerintah Provinsi Jawa Timur, T.tf: 3 ).

Selain program Kualifikasi Guru Madin, Provinsi Jawa Timur juga memiliki program Bantuan Penyelenggaraan Pendidikan Diniyah dan Guru Swasta (BPPDGS) yang maksud dan tujuannya memberikan bantuan biaya operasional penyeleggaraan pendidikan sesuai dengan kebutuhan mendasar dan pokok bagi warga pendidikan Diniyah, sebagaimana dinyatakan bahwa: "Program BPPDGS bermaksud untuk memberikan bantuan biaya operasional penyelennggaraan pendidikan sesuai dengan kebutuhan mendasar dan pokok bagi Santri/Warga Belajar/Siswa Madrasah Diniyah Takmiliyah Ula/Wustho, Paket A/B dan Paket A/B Pondok Pesantren, Ustadz/Guru Madrasah Diniyah Takmiliyah Ula/Wustho dan Guru Swasta SD/MISDLB/ SLB/Salafiyah Ula/SMP/MTs /SMPLB/ Salafiyah Wustho Swasta dan Guru SMP Satu Atap/MTs Satu Atap" (Dinas Pendidikan Provinsi Jawa Timur, 2016:9).

\section{Al-Islam dan Kemuhammadiyahan}

Muhammadiyah merupakan organisasi Islam, dakwah amar makruf nahi munkar dan mneyebarkan islam rahmatan lil alamin. Meskipun pendekatan Muhammadiyah bermacam-macam sesuai dengan aktivitasnya, Jati diri muhammadiyah berimplikasi pada ruang gerak dan aktivitasnya dalam multi aspek kehidupan, sesuai dengan kebutuhan manusia atau masyarakat (Syaifullah, 1997:2). Menurut Deliar Noer salah satu organisasi sosial Islam yang terpenting di Indonesia sebelum Perang Dunia II adalah Muhammadiyah dan mungkin juga sampai saat ini (Deliar Noer, 1990:84), sementara Mitsuo Nakamura menyebutnya sebagai organisasi "masyarakat sipil Islam" terbesar kedua di Indonesia (the second largest Islamic society organization) in Indonesia) (Mitsuo Nakamura, 2012:xx). Dalam pandangan Rheinald Kasali, Muhammadiyah memiliki kemampuan menciptakan perubahan (change) terutama dari dalam, dengan catatan tidak mengubah jati dirinya sehingga tetap memiliki kekuatan dialektis dengan perubahan dari luar yang tidak pernah mengenal kata henti (Rheinald Kasali, 2007:12).

Dalam Jurnal Al-Idarah (Arifin dkk, 2017) menyatakan Islam yang ditawarkan Muhammadiyah adalah Islam yang sistemik, yaitu Islam yang ajarannya Al-Islam Dan Kemuhammadiyahan bersifat multidime nsional, dari sisi materinya meliputi dimensi intelektual, ideologikal, mistikal, etikal, dan sosial. Jika dilihat dari aspek proses pembelajarannya al-Islam dan kemuhammadiyahan meliputi transfer of knowledge, transfer of values,tranfer of attitude, dan transfer of experience. Dari aspek pembentukan kepribadian meliputi dimensi kognitif, afektif, dan psikomotor. Sedangkan dari aspek misi yang diemban dosen dan lembaga Perguruan Tinggi Muhammadiyah pembelajaran al-Islam dan kemuhammadiyahan meliputi misi dakwah, misi kemanusiaan, misi keilmuan, misi kebangsaan dan kenegaraan (Leonita Siwiyanti, 2015: 144).

Dibutuhkan desain pembelajaran Al-Islam dan Kemuhammadiyahan yang memiliki karakeristik sebagai upaya mencakup kemultidimensionalnya, diataranya: 1) Pembelajaran AIK yang berparadigma spiritualitas tauhid dan etika sosial; 2) Pembelajaran AIK untuk membangun karakter kuat sebagai muslim yang berkemajuan, berakhlak mulia, berjiwa kepemimpinan, bermisi dakwah amar makruf nahi munkar dan memiliki komitmen 
sebagai kader persyarikatan; 3) Pembelajaran AIK yang kontekstual untuk membangun kejayaan pribadi, masyarakat, bangsa dan negara; 4) Pembelajaran AIK yang menyenangkan, mencerdaskan, dan konstruktif yang didukung oleh desain kurikulum yang standar, dosen-dosen yang kompeten, sumber belajar yang mendukung dan kebijakan yang kondusif.

Oleh karena itu dengan desain pembelajaran AIK tersebut diharapakan akan memberikan pengaruh terhadap peningkatan akhlak karimah dalam kehidupan sehari-hari mahasiswa berupa: sikap taat dalam beribadah, kepedulian dengan sesama manusia, dan kedisiplinan dalam menjalankan tugas dan aturan yang ada.

Dalam menanamkan nilai-nilai keislaman kepada mahasiswa sangat penting untuk meningkatkan kualitas pembelajaran pada kurikulum Al-Islam dan Kemuhammadiyahan. Kulaitas pembelajaran matakuliah AIK adalah pondasi dalam diri mahasiswa dalam meningkatkan sikap religiusitas. Kita melihat realita yang terjadi saat ini masih banyak mahasiswa yang ketika pembelajaran berlangsung namun masih banyak yang tidak serius bahkan mahasiswa tersebut tidak serius dalam kegiatan pembelajara, hal inilah yang menjadikan mahasiswa tidak mempunyai karakter yang baik dalam dirinya. Kiita harus mempunyai nilai tanggungjawab dalam mendidik mahasiswa pada zaman modern ni sehingga mereka tidak terjerumus kedalam perbuatan yang negatif dan mereka bisa menjadi mahasiswa yang cerdas, berpendidikan dan mempunyai moral serta akhlak yang mulia. Inilah pendidikan Islam yang berkemajuan. IPTEKS adalah hasil pemikiran rasional secara holistik dan komprehensif atas realitas alam semesta (ayat kauniyah) dan atas wahyu dan sunnah (ayat qauliyah) yang merupakan satu kesatuan.

Oleh karena itu Al-Islam dan Kemuhammadiyahan (AIK) Merupakan Matakuliah wajib bagi semua Universitas Muhammadiyah seIndonesia, termasuk Sekolah Tinggi Ilmu Tarbiyah (STIT) Muhammadiyah Bojonegoro yang ditempuh 2 semester, yaitu Kemuhammadiyahan 1 (Aqidah, Akhlak dan Ibadah) dan Kemuahmmadiyahan 2 (muammalah duniawiyah).

\section{Aplikasi Pendidikan Al-Islam dan Kemuhammadiyahan}

Pertanyaan tentang latar belakang dan tujuan pendidikan AIK bagi mahasiswa terhadap salah satu Dosen AIK dalam wawancaranya menyatakan bahwa: "Latar belakang mungkin yang sangat berhubungan dengan karakteristik mahasiswa. Dalam hal ini kompeten itu bukan hanya keterampilan atau pengetahuan tetapi sikap. Jadi dengan adanya Al-Islam dan Kemuhammadiyahan ini sikap mahasiswa diharapkan sekarang dan nanti setelah lulus menjadi manusia yang betul-betul bisa mengaplikasikan apa yang didapat selama pelajaran Al-Islam dan Kemuhammadiyahan" (Hasil wawancara dengan Ibu Nur Mashani Mustafidah, M.Pd.I dosen Kemuhammadiyahan I STIT Muhammadiyah Bojonegoro. Senin, 4 Januari 2021).

Dosen pengampu mata kuliah AIK mengaharapkan materi AIK yang telah disampaikan dapat mencetak mahasiswa yang unggul dalam bidangnya dan dapat memperbaiki sikap mahasiswa, sehingga mahasiswa memilki kepedulian sosial dan berperan aktif di kehidupan bermasyarakat.

Tujuan dan harapan tersebut memilki kesamaan dengan Visi Perguruan 
Tinggi Muhammadiyah tentang Revitalisasi Pendidikan Muhammadiyah sebagaimana tertuang dalam blue print Putusan Muktamar Muhammadiyah ke-46 tahun 2010 di Yogjakarta, yaitu: "Terbentuknya manusia pembelajar yang bertaqwa, berakhlak mulia, berkemajuan dan unggul dalam iptek sebagai perwujudan tajdid dakwah amar makruf nahi munkar. Sedangkan rumusan Majelis Dikti Pimpinan Pusat Muhammadiyah tentang Visi Perguruan Tinggi Muhammadiyah adalah terbangunnya tata kelola Perguruan Tinggi Muhammadiyah yang baik (good governance) menuju peningkatan mutu berkelanjutan. Sebagai perguruan tinggi dibawah Persyarikatan Muhammadiyah, Perguruan Tinggi Muhammadiyah mengemban misi untuk mewujudkan misi Muhammadiyah yaitu menyelenggarakan pendidikan Al-Islam dan Kemuhammadiyahan sebagai bagian dari dakwah amar makruf nahi munkar dalam pengertian yang seluas-luasnya.

Ketua STIT Muhammaiyah Bojonegoro yang juga dosen pengampu mata kuliah Kemuhammadiyahan 2, ditanyakan di STIT Muhammadiyah Bojonegoro termasuk mata kuliah apa mata kuliah Al-Islam dan Kemuhammadiyahan itu?, berapa semester dilaksanakan?, dan bagaimana pembagiannya? "Pendidikan Al-Islam dan Kemuhammadiyahan di sini (STIT Muhammadyah Bojonegoro-red) sebagai penciri khusus mata kuliah di Perguruan Tinggi Muhammadiyah, yang sangat mendukung sekali mahasisiwa dalam membentuk insan yang mulia, mata kuliah AIK ini dibagi menjadi 4 SKS yang terdiri dari Kemuhammadiyahan I (Aqidah, Akhlak, dan Ibadah), dan Kemuhammadiyahan II (muammalah). (Hasil wawancara dengan Bapak Drs. H. Ihwanuddin, M.Pd.I dosen Kemuhammadiyahan II, Rabu, 6 Januari 2021).
Pada awalnya pendidikan Al-Islam dan Kemuhammadiyahan di STIT Muhammadiyah Bojonegoro hanya dimasukkan sebagai Muatan Lokal, namun seiring berjalannya waktu sudah dimasukkan ke dalam kurikulum institusional. Di dalamnya, meliputi mata kuliah Al-Qur'an, Akidah, Akhlak, Ibadah, dan Kemuhammadiyahan. Selain hal tersebut, pembahasan mata kuliah ini diperluas dengan pengembangan akan pemahaman, penerapan, dan praktik membaca Al-Qur'an. Pada akhir perkuliahan ini, mahasiswa bisa lancar membaca Al-Qur'an, memahami isi AlQur'an, mampu menerapkan dan mempraktekan dalam kehidupan sehari-hari untuk dirinya, keluarga maupun masyarakat sebagai perwujudan dakwah Islam. Khusus untuk semester II, ditambahkan mata kuliah ibadah, yang membahas tentang thaharah, shalat, shalat jama'ah, macam-macam sujud, salat fardu dalam shafar, do'a-do'a, zakat, infak, sodaqoh, puasa, haji, dan umroh. Penekanannya, dalam pelaksanaan shalat, diharapkan mahasisiwa selain dapat melaksanakan shalat tepat waktu dan sesuai dengan tuntunan Rasullullah, namun juga mengetaui apa yang dibacanya dari takbir sampai salam. Pada pelaksanaan pendidikan Kemuhammadiyahan membahas riwayat KH. Ahmad dahlan serta produk pemikirannya sebagai reformer yang melahirkan Muhammadiyah kemudian perkembangannya Muhammadiyah serta peran dan perjuangan tokoh dan organisasi Muhammadiyah dalam sejarah perkembangan Indonesia. Selain itu dibahas pula hakikat, fungsi dan misi Muhammadiyah serta konsep-konsep yang mempertegas kepribadian Muhammadiyah. Sehingga diharapkan mahasiswa akan mengamalkan akhlak yang terpuji sehingga dapat menggugah sem angat baru dalam ber-Muhammadiyah. Pada semester III, diberikan materi akidah 
akhlak. Mata kuliah ini membahas tentang pengenalan agama, malaikat, kitab-kitab Allah, Nabi dan rasul, akhlak pribadi, akhlak dalam keluarga, akhlak bermayarakat, bertamu, bertetangga, dan bernegara, hari akhir dan takdir. Pemahaman akan akidah haruslah diselaraskan dengan pengetahuan akan dasar hukumnya (dalil) sehingga mahasiswa tidak lagi bersifat taklid (ikutikutan tanpa mengetahui dasar hukum atas persoalan akidah akhlak) tetapi sudah dapat menerapkan dan menjalankan dengan mengetahui dasar hukum nya. Antara akhlak dan aqidah terdapat sebuah korelasi. Bila akidah sudah kuat, maka akan muncul akhlak yang baik.

Pelaksanaan pendidikan Al-Islam dan Kemuhammadiyahan sejalan dengan konsep perkembangan peserta didik. Kata perkembangan seringkali dikaitkan dengan pertumbuhan dan kematangan. Pertumbuhan dan perkembangan pada dasarnya adalah perubahan menuju ke tahap yang lebih tinggi atau lebih baik. Ada beberapa perbedaan antara pertumbuhan dengan perkembangan.

Pertumbuhan lebih banyak berkenaan dengan aspek-aspek jasmaniah atau fisik, sedang perkembangan dengan aspek-aspek psikis atau rohaniah. Pertumbuhan menunjukkan perubahan atau penambahan secara kuantitas, yaitu penambahan dalam ukuran besar atau tinggi, sedang perkembangan berkenaan dengan peningkatan kualitas, yaitu peningkatan dan penyempurnaan fungsi. Perkembangan individu berlangsung berlangsung sepanjang hayat, dimulai sejak masa pertemuan sel ayah dengan ibu dan berakhir pada saat kematiannya. Perkembangan manusia itu dinamis,perubahannya bisa lambat maupun cepat dan perkembangan tiap indiividu tidak selalu sama satu sama lainnya.
Perkembangan dipengaruhi faktor pembawaan dan juga faktor lingkungan.

STIT Muhammadiyah Bojonegoro berusaha menciptakan sebuah lingkungan yang dapat mempercepat perkembangan perilaku keberagamaan mahasiswanya. Usia mereka adalah masa remaja, yakni masa peralihan antara masa anak dengan dewasa. Meskipun berkembangan aspekaspek kepribadian itu telah diawali pada masa-masa sebelumnya, tetapi puncaknya terjadi pada masa remaja, sebab setelah melewati masa ini, remaja telah berubah menjadi dewasa. Karena peranannya sebagai masa transisi antara masa anak dan dewasa, maka pada masa ini terjadi berbagai gejolak atau kemelut. Gejolak atau kemelut ini terutama berkenaan dengan segi afektif, sosial, intelektual juga moral.

Pendidikan Al-Islam dan Kemuhammadiyahan di STIT Muhammadiyah Bojonegoro membantu mahasiswa melewati masa transisi yang penuh gejolak dengan baik. Selama di kampus para mahasiswa mengalami latihan kehidupan bermasyarakat dalam bentuk miniatur. Hal ini akan sangat bermanfaat bagi para mahasiswa sebagai pengalaman dalam mempersiapkan diri untuk menyongsong kehidupan yang sesungguhnya di masyarakat kelak. Para mahasiswa menemukan berbagai macam latar belakang kehidupan ekonomi, sosial, dan budaya yang tidak selamanya sama dengan yang dimiliki oleh dirinya hal ini mendorong mereka memahami dan menyesuaikan sikap dan perilaku dirinya dalam berhubungan dengan teman-teman yang lain, dengan demikian akan memunculkan sikap perilaku yang toleran dan ta'awun.

Oleh karenanya sudah tepat
kirannya kebijakan dari STIT
Muhammadiyah Bojonegoro menginginkan
lulusannya tidak hanya terampil dalam 
bidang umum tapi juga dalam hal agama Islam. Hal ini dapat menguntungkan Persyarikatan Muhammadiyah dalam proses syiarnya, dan juga meningkatkan tingkat kepercayaan masyarakat atas STIT Muhammadiyah Bojonegoro.

Berdasarkan hasil wawancara mendalam dengan narasumber di atas, implementasi Pendidikan Al-Islam dan Kemuhammadiyahan dapat dideskripsikan sebagai berikut, kedudukan mata kuliah AlIslam dan Kemuhammadiyahan yang pada mulanya hanya mata kuliah muatan lokal, yang sifatnya hanya kegiatan tentatif tidak mengikat menjadi mata kuliah instutisional, yang wajib diikuti oleh mahmenjadi mata kuliah yang menjadi ciri khas dari Perguruan Tinggi Muhammadiyah. Selanjutnya, di semester I, ada mata kuliah Pendidikan Agama Islam dan bagi mahasisiwa yang belum lulus Baitul Arqam atau yang belum mengikutinya, maka mahasiswa tidak bisa mengambil mata kuliah AIK I di semester II dan seterusnya.

Setelah mendapat pendidikan AlIslam dan Kemuhammadiyahan, mahasisiwa diharapkan dapat memahami, menghayati, mempraktekkan nilai-nilai AlIslam dan Kemuhammadiyahan, baik dalam menjelaskan pemahaman, mempraktekan keterampilan tertentu, ataupun mengamalkan nilai-nilai baik dalam menjalankan amalan yang diperintahkan maupun meninggalkan perbuatan yang dilarang. Oleh karena itu penilaian yang diberikan oleh dosen AlIslam dan Kemuhammadiyahan adalah penilaian yang bersifat akumulatif, dari nilai ujian praktek Al-Islam dan Kemuhammadiyahan, data bukti atau catatan pelanggaran mahasiswa, maupun perilaku mereka. Sehingga penilaian itu menggambarkan keseluruhan perilaku mahasiswa dalam seluruh aspek kehidupannya. Nilai-nilai tadi diimplementasikan ketika mereka mengikuti praktek kerja lapangan baik itu di bidan praktek swasta, maupun sarana pelayanan lainny, mereka juga mampu menampilkan perilaku sebagai wujud dari penghayatan dan pemahaman terhadap nilai-nilai dari Pendidikan Al-Islam dan Kemuhammadiyahan. Sehingga sikap dan perilaku keberagamaan mahasiswa STIT Muhammadiyah Bojonegoro dapat dibedakan dengan mahasisiwa perguruan tinggi yang lainnya.

\section{Respon Mahasiswa Program Kualifikasi Guru Madin Terhadap Mata Kuliah AIK}

Respon adalah suatu kegiatan (activity) dari organisme itu bukanlah semata-mata suatu gerakan yang positif, setiap jenis kegiatan (activity) yang di timbulkan oleh suatu perangsang dapat juga disebut respon. Secara umum respon atau tanggapan dapat diartikan sebagai hasil atau kesan yang di dapat (ditinggal) dari pengamatan tentang subjek, peristiwa atau hubungan-hubungan yang diperoleh dengan menyimpulkan informasi dan menafsirkan pesan-pesan (Djalaludin Rakhmat, 1999:51). Dan yang di maksud Respons Mahasiswa Madin adalah tanggapan, reaksi, jawaban mahasiswa terhadap matakuliah Al-Islam dan Kemuhammadiyahan (AIK) dan penghayatan terhadap nilai-nilai agama Islam.

Dari hasil wawancara dengan Ketua STIT Muhammadiyah Bojonegoro Drs. H. Ihwanuddin, M.Pd.I yang juga Dosen Kemuhammadiyahan II bahwa latar belakang hampir semuanya berlatar Belakang Nahdlatul Ulama (NU), dikarenakan Madrasah Dieniyah yang ada di Bojonegoro mayoritas berafiliasi ke NU. Hal itu dibuktikan dengan hasil wawancara dan dokumentasi penerimaan Mahasiswa Baru tahun 2018 dari 29 Mahasiswa Madin yang lulus 27 Mahasiswa berasal dari 
Madin NU dan 2 Mahasiswa berasal dari Madin Muhammadiyah. Secara keorganisasian mahasiswa belum banyak mengenal Muhammadiyah, hanya sebatas tahu bahwa Muhammadiyah adalah Organisasi Islam Kemasyarakatan dan tidak mengetahui adanya materi tentang Kemuhammadiyahan.

Nur Mashani Mustafidah, M.Pd.I Dosen Kemuhammadiyahan I menjelaskan bahwa dengan mahasiswa berlatar belakang NU maka perlu adanaya perhatian khusus dalam menyampaikan Materi AIK, dimulai materi yang bersifat Umum berupa pengenalan, informasi, dan contoh konkrit dalam kehidupan sehari-hari serta dihindari materi-materi perkulihan yang sifatnya perbedaan khilfiyah dalam Aqidah dan Ibadah. Jika materi yang sifatnya umum tersebut disampaikan maka akan terjadi pemahaman sehingga mereka akan mnerima dengan baik meskipun ada perbedaan dalam hal organisasi. (Hasil wawancara dengan Ibu Nur Mashani Mustafidah, M.Pd.I dosen Kemuhammadiyahan I STIT Muhammadiyah Bojonegoro. Senin, 4 Januari 2021).

Dari data yang diperoleh peneliti melalui angket kuisioner tentang respon Mahasiswa Kualifikasi Guru Madrasah Dieniyah terhadap Matakuliah AIK, diperoleh

Table 1. Deskripsi Respon Mahasiswa

\begin{tabular}{|c|c|c|c|}
\hline Indikator & Jenis Pertanyaan & $\begin{array}{l}\text { Iya/ } \\
\text { Sesuai/ } \\
\text { Baik }\end{array}$ & $\begin{array}{c}\text { Tidak/ } \\
\text { Tidak } \\
\text { Sesuai/ } \\
\text { Tidak } \\
\text { baik } \\
\end{array}$ \\
\hline \multirow{5}{*}{$\begin{array}{c}\text { Penerimaan Mahasiswa } \\
\text { terhadap Matakuliah } \\
\text { Kemuhammadiyahan } \\
\end{array}$} & $\begin{array}{l}\text { Mahasiswa Mengenal Materi } \\
\text { KeMuhammadiyahan }\end{array}$ & $90 \%$ & $10 \%$ \\
\hline & $\begin{array}{lr}\text { Mahasiswa menerima } & \text { adanya } \\
\text { mata } & \text { kuliah } \\
\text { Kemuhammadiyahan } & \\
\end{array}$ & $98 \%$ & $2 \%$ \\
\hline & $\begin{array}{l}\text { Perlunya matakuliah } \\
\text { Kemuhammadiyahan } \\
\text { disampaikan kepada Mahasiswa }\end{array}$ & $74 \%$ & $26 \%$ \\
\hline & $\begin{array}{l}\text { Matakuliah Kemuhammadiyahan } \\
\text { dapat membuka wawasan baru } \\
\text { tentang organisasi }\end{array}$ & $96 \%$ & $4 \%$ \\
\hline & $\begin{array}{l}\text { Mahasiswa senang mendapatkan } \\
\text { Matakuliah Kemuhammadiyahan }\end{array}$ & $70 \%$ & $30 \%$ \\
\hline Rata-rata & & $85,6 \%$ & $14,4 \%$ \\
\hline \multirow[t]{6}{*}{$\begin{array}{l}\text { Pelaksanaan } \\
\text { Pembelajaran AIK }\end{array}$} & $\begin{array}{l}\text { Penyampaian materi AIK oleh } \\
\text { Dosen }\end{array}$ & $97 \%$ & $3 \%$ \\
\hline & $\begin{array}{l}\text { Metode yang dipakai dalam } \\
\text { pembelajaran AIK }\end{array}$ & $96 \%$ & $4 \%$ \\
\hline & $\begin{array}{l}\text { Dosen menyampaikan } \\
\text { pemahaman Muhammadiyah }\end{array}$ & $96 \%$ & $4 \%$ \\
\hline & $\begin{array}{l}\text { Dosen tidak menyalahkan } \\
\text { pemahaman Organisasi lain } \\
\text { (NU-red) }\end{array}$ & $99 \%$ & $1 \%$ \\
\hline & $\begin{array}{l}\text { Materi Kemuhammadiyahan } \\
\text { mengutamakan } \\
\text { ditengah perbedaan }\end{array}$ & $98 \%$ & $2 \%$ \\
\hline & $\begin{array}{lrr}\text { Mengutamakan } & \text { kepentingan } \\
\text { negara daripada } & \text { perbedaan }\end{array}$ & $98 \%$ & $2 \%$ \\
\hline
\end{tabular}




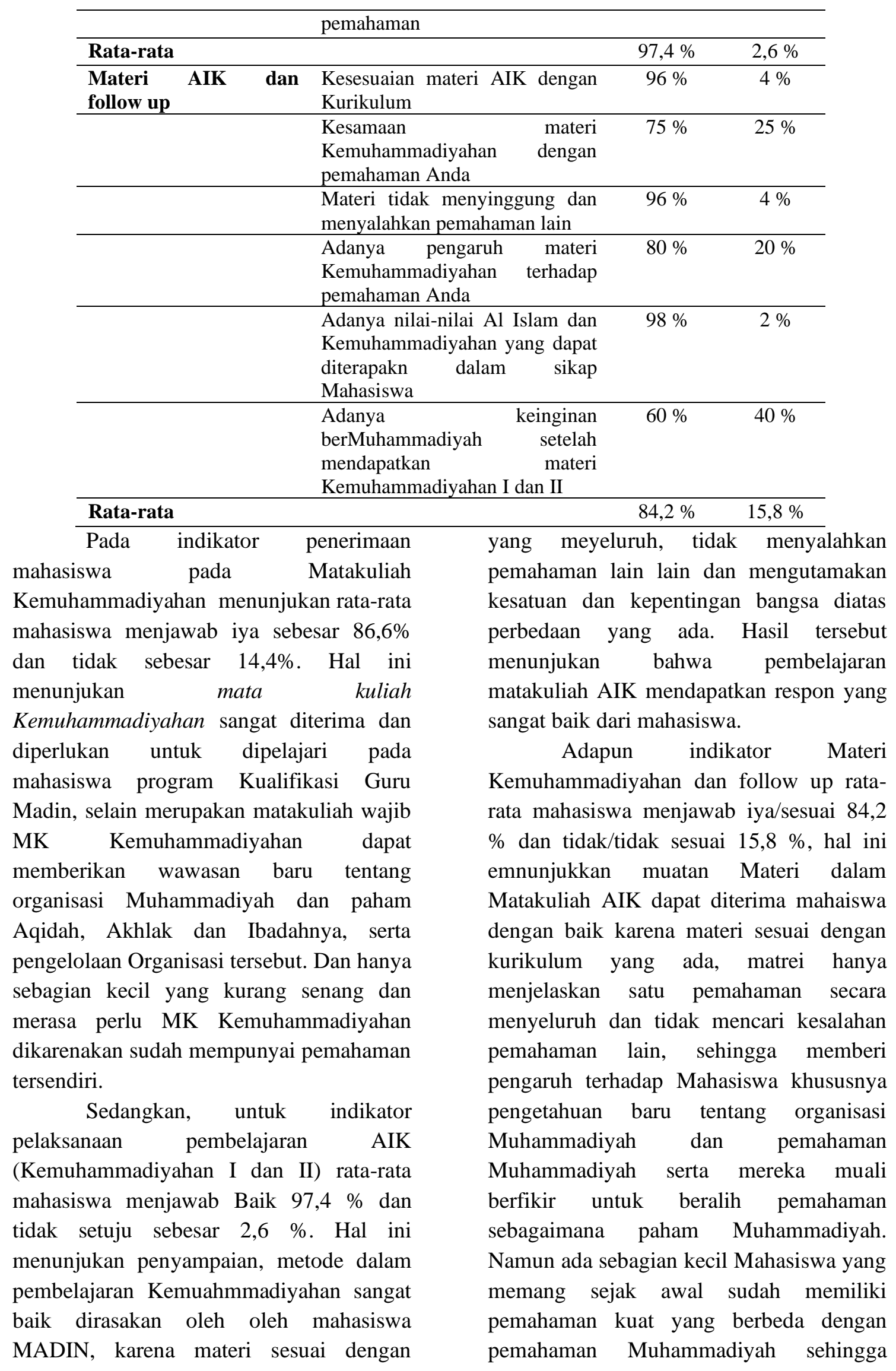


tidak terpengaruh untuk beralih pemahaman.

Penelitian ini juga menunjukan dengan diberikannya AIK, maka mahasiswa yang memang berlatar belakang Muhammadiyah lebih mengerti secara mendalam tentang AIK, sedang bagi mereka yang bukan berlatarbelakang Muhammadiyah menjadi paham tentang apa yang selama ini dan akan diperjuangkan oleh Muhammadiyah. Dan memang pembejaran AIK buakn untuk menjadikan Mahasiswa masuk alam Organisasi/Persyarikatan Muhammadiyah, tetapi hanya memberikan informasi tentang oragnisasi tersebut serta pemahamannya.

Di samping itu juga diharapkan AIK dapat membimbing mahasiswa menjadi pribadi yang muttaqin, yakni manusia yang bertanggungjawab untuk meneruskan ajaran Rasulullah serta dapat menambah wawasan mahasiswa tentang organsasi keislaman, memberi pemahaman kepada mahasiswa bahwa Muhammadiyah merupakan gerakan Islam modern yang berupaya untuk mengembalikan kemurnian Islam dari pengaruh-pengaruh ajaran yang sesat dengan berlandaskan pada al-Qur'an dan Hadits Rasul".

\section{SIMPULAN}

Al-Islam dan Kemuhammadiyahan merupakan mata kuliah wajib sekaligus matakuliah penciri Perguruan Muhammaiyah se-Indonesia. AIK di perguruan Tinggi Muhammadiyah sejalan dengan tujuan pendidikan agama di perguruan tinggi yaitu memberikan landasan pengembangan kepribadian kepada mahasiswa agar menjadi kaum intelektual yang beriman dan bertaqwa kepada Tuhan Yang Maha Esa, berbudi pekerti luhur, berfikir filosofis, bersikap rasional dan dinamis, berpandangan luas, ikut serta dalam kerjasama antar umat beragama dalam rangka pengembangan dan pemanfaatan ilmu dan teknologi serta seni untuk kepentingan nasional.

Adapun pelaksanaan pembelajaran AIK di Sekolah Tinggi Ilmu Tarbiyah (STIT) Bojonegoro berjalan dengan baik, yang meliputi mata kuliah kemuhammadiyahan I dan Kemuhammadiyahan II dan berikan pada seluruh mahasiswa disemua program Studi, khususnya kepada mahaiswa Program Kualifikasi Guru Madrasah Diniyah Provinsi Jawa Timur.

Respon mahasiswa Kualifikasi Guru Madin yang mayoritas berlatar belakang Nahdlatul Ulama (NU) sangat baik, dibuktikan dengan indikator penerimaan mata kuliah AIK sebesar 85,4 \%, indikator pembelajaran AIK oleh Dosen sebesar 97,4 $\%$, dan -ndikator Materi AIK dan follow-up sebesar 84,2\%. Dapat diartikan bahwa mahaiswa dapat menerima mata kuliah dengan baik dikarenakan dapat menambah wawasan baru tentang organisasi Muhammadiyah serta pengelolaannya, juga memperoleh pemahaman yang baru tentang kegamaan, meliputi Aqidah, akhlak, ibadah dan muammalah, serta materi tidak menyinggung dan menyalahkan pemahaman laian. Selain itu beberapa mahasiswa mulai berfikir untuk ber "Muhammadiyah" setelah mendapatkan mata kuliah AIK. Akan tetapi terdapat sebagian kecil mahasiswa yang emberikan respon kurang baik, dikarenakan mereka telah meiliki pemahaman yang kuat sehingga AIK hanya dianggap seperti matakuliah lainnya dan dengan pemahaman yang kuat mereka tidak mempunyai keinginan ber "Muhammadiyah".

\section{DAFTAR RUJUKAN}

Arifin dkk,. (2017). Internalisasi NilaiNilai Modernitas Dalam Gerakan Dakwah Organisasi Muhammadiyah Di Aceh, Al-Idarah : Jurnal Manajemen dan Administrasi Islam. 
Bappeda Jatim. Rencana Pembangunan Jangka Mengengah Daerah (RPJMD) Provinsi Jawa Timur 2014-2019

Dinas Pendidikan Provinsi Jawa Timur. (2015). Laporan Hasil Monitoring dan Evaluasi Madin Jawa Timur 2015. Surabaya: Dinas Pendidikan Provinsi Jawa Timur.

Dinas Pendidikan Provinsi Jawa Timur. (2016). Pedoman Teknis Bantuan Penyelenggaraan Pendidikan Diniyah dan Guru Swasta Tahun 2016. Surabaya: Dinas Pendidikan Provinsi Jawa Timur.

Fariadi. (2010). Persepsi Mahasiswa Terhadap Mata Kuliah Al Islam Dan Kemuhammadiyahan (Aik) : Internalisasi Nilai-Nilai Aik Bagi Mahasiswa. Jurnal PROGRESIVA Vol. 4, No.1.

Kasali, Rheinald. (2007). Re-Code Your Change DNA: Membebaskan Belenggu-belenggu untuk Meraih Keberanian dan Keberhasilan dalam Pembaharuan. Jakarta: Gramedia.

Leonita Siwiyanti, (2015). Peran Studi AlIslam Dan Kemuhammadiyahan Dalam Pembentukan Akhlak Mahasiswa Universitas Muhammadiyah Sukabumi. Utile Jurnal Kependidikan.

Lexy J Moleong. (2007). Metodologi Penelitian Kualitatif. Bandung: PT. Remaja Rosdakarya.

M. Nafiur Rofiq. ( 2011). Eksistensi Kebijakan Pemerintah Provinsi Jawa Timur terhadap Peningkatan Kualifikasi Akademik Guru Madrasah Diniyah di Jawa Timur. JURNAL FALASIFA. Vol. 2 No. 1

Miles, Mattew B dan A. Michael Huberman. (2007). Analisis Data Kualitatif,. Buku sumber tentang metode- metode baru. Jakarta: Universitas Indonesia. Press.
Nakamura, Mitsuo (2012). The Crescent Arises over the Banyan Tree: A Study of the Muhammadiyah Movement in a Central Javanase Town, c. 1910s2010. Singapore: ISEAS.

Noer, Deliar. (1990). Gerakan Moderen Islam di Indonesia ; 1900-1042. Jakarta: LP3ES.

Pemerintah Provinsi Jawa Timur. (T.th). Pedoman Penyelenggaraan Program Peningkatan Kualitas Guru Madrassah Diniyah Provinsi Jawa Timur. Surabaya: Biro Administrasi Kemasyarakatan.

Rakhmat, Djalaludin. (1999). Psikologi Komunikasi. Bandung: Remaja Rosda Karya.

Rofiq, M. Nafiur. 2011. Eksistensi Kebijakan Pemerintah. JURNAL FALASIFA. Vol. 2 No.1.

Suharto, Toto. (2014). Gagasan Pendidikan Muhammadiyah dan NU sebagai Potret Pendidikan Islam Moderat di Indonesia. Surakarta: Jurnal Studi KeIslaman. p.81-109.

Syaifullah. (1997). Gerak politik Muhammadiyah dalam Masyumi. Jakarta : Pustaka utama Grafiti.

Syamsul Hidayat, dkk. (2012). Studi Kemuhammadiyahan: Kajian Historis Ideologi dan Organisasi. Surakarta: LPID UMS.

Tim Pedoman Pendidikan Al-Islam dan Kemuhammadiyahan. (2013). Pendidikan Al-Islam dan Kemuhammadiyahan perguruan tinggi muhammadiyah. Yogyakarta: Majelis pendidikan tinggi PP muhammadiyah.

Tri Saswandi, Ayu Permata Sari. (2019). Analisis penerapan nilai-nilai $\mathrm{Al}$ Islam dan Kemuhammadiyahan dalam perkuliahan. Jurnal EDUCATIO Jurnal Pendidikan Indonesia. Volume 5 Nomor 1. DOI: https://doi.org/10.29210/120192327 
138 JURNAL PENDIDIKAN EDUTAMA, Vol.8, No.1 Januari 2021

p-ISSN 2476-9886 e-ISSN 2477- Wahyuddin, et.all. (2009). Pendidikan $\underline{0302}$ Agama Islam Untuk Perguruan Tinggi. Jakarta: PT. Gramedia. 